OPEN ACCESS

Edited by:

Kimberly Raab-Graham, Wake Forest School of Medicine, USA

Reviewed by:

Tobias Engel,

Royal College of Surgeons in Ireland,

Ireland

Christina Gross,

Cincinnati Children's Hospital Medical

Center, USA

*Correspondence: Xuefeng Wang

xfyp@163.com

Received: 25 October 2016 Accepted: 23 March 2017

Published: 07 April 2017

Citation:

Zhang Y, Gao B, Zheng F, Lu S, Li Y, Xiong $Y$, Yang $Q$, Yang $Y, F u$,

Xiao F and Wang $X$ (2017)

The Phosphodiesterase 10A Inhibitor PF-2545920 Enhances Hippocampal

Excitability and Seizure Activity Involving the Upregulation of G/uA1 and NR2A in Post-synaptic Densities.

Front. Mol. Neurosci. 10:100.

doi: 10.3389/fnmol.2017.00100

\section{The Phosphodiesterase 10A Inhibitor PF-2545920 Enhances Hippocampal Excitability and Seizure Activity Involving the Upregulation of GluA1 and NR2A in Post-synaptic Densities}

\author{
Yanke Zhang', Baobing Gao' ${ }^{2}$, Fangshuo Zheng', Shanshan Lu', Yun Li', Yan Xiong', \\ Qin Yang ${ }^{1}$, Yong Yang ${ }^{1}$, Pengfei Fu' ${ }^{1}$, Fei Xiao ${ }^{1}$ and Xuefeng Wang ${ }^{1,3,4 *}$
}

1 Department of Neurology, The First Affiliated Hospital of Chongqing Medical University, Chongqing, China, ${ }^{2}$ Department of Neurology, Chongqing General Hospital, Chongqing, China, ${ }^{3}$ Center of Epilepsy, Beijing Institute for Brain Disorders, Beijing, China, ${ }^{4}$ Chongqing Key Laboratory of Neurology, Chongqing, China

Phosphodiesterase regulates the homeostasis of cAMP and CGMP, which increase the strength of excitatory neural circuits and/or decrease inhibitory synaptic plasticity. Abnormally, synchronized synaptic transmission in the brain leads to seizures. A phosphodiesterase 10A (PDE10A) inhibitor PF-2545920 has recently attracted attention as a potential therapy for neurological and psychiatric disorders. We hypothesized that PF-2545920 plays an important role in status epilepticus (SE) and investigated the underlying mechanisms. PDE10A was primarily located in neurons, and PDE10A expression increased significantly in patients with temporal lobe epilepsy. PF-2545920 enhanced the hyperexcitability of pyramidal neurons in rat CA1, as measured by the frequency of action potentials and miniature excitatory post-synaptic current. GluA1 and NR2A expression also increased significantly in post-synaptic densities, with or without SE in rats treated with PF-2545920. The ratio of $p$ GluA1/GluA1 increased in the presence of PF-2545920 in groups with SE. Our results suggest that PF-2545920 facilitates seizure activity via the intracellular redistribution of GluA1 and NR2A in the hippocampus. The upregulation of $p$-GluA1 may play an important role in trafficking GluA1 to post-synaptic densities. The data suggest it would be detrimental to use the drug in seizure patients and might cause neuronal hyperexcitability in non-epileptic individuals.

Keywords: PF-2545920, status epilepticus, rat model, GluA1, NR2A

\section{INTRODUCTION}

Phosphodiesterases (PDEs), which hydrolyze cyclic AMP (cAMP) and/or cyclic guanosine monophosphate (cGMP), contain 11 isozymes encoded by 21 genes in mammals (Seeger et al., 2003; Bender and Beavo, 2006). Phosphodiesterase 10A (PDE10A) degrades both cAMP and cGMP but has a much higher affinity for cAMP (Soderling et al., 1999; Conti and Beavo, 2007; Francis et al., 2011). PDE10A is found in different multiple regions of the brain in mammalian species, 
including the striatal neuropil, substantia nigra, hippocampus, and cortex (Seeger et al., 2003). Several studies have demonstrated that PDE10A inhibitors upregulate cAMP and cGMP concentrations in the striatum (Siuciak et al., 2006; Grauer et al., 2009) and hippocampus (Liddie et al., 2012). PDE10A is found predominantly in the mammalian brain, suggesting that it has multiple functions in the central nervous system (CNS), especially in striatum-dependent behavioral phenomena (Siuciak et al., 2006; Leuti et al., 2013; Garcia et al., 2014). Recent studies demonstrated a putative role for PDE10A in the treatment of neurological and psychiatric disorders. Numerous PDE10A inhibitors have been verified as candidate drugs for the treatment of schizophrenia in animal or preclinical research (Siuciak et al., 2006; Giralt et al., 2013). PDE10A may be involved in other neurological and psychiatric disorders, including Huntington's disease (Leuti et al., 2013; Ahmad et al., 2014; Niccolini et al., 2015), Parkinson's disease (Garcia et al., 2014; Niccolini et al., 2015), addiction (Liddie et al., 2012; Logrip et al., 2014), and Lesch-Nyhan disease (Guibinga et al., 2013). PDE10A is also involved in improving spatial and recognition memories (Rodefer et al., 2012; Giralt et al., 2013) and appetite regulation (Piccart et al., 2011, 2013). Moreover, inhibitors of PDE10A may be useful for the treatment or prevention of colorectal cancer (Li et al., 2015). Cyclic nucleotides, including cAMP and cGMP, act as second messenger signaling molecules and participate in numerous cellular functions in the CNS, including neurotransmitter specification, axon guidance, and refinement of neuronal connectivity (Averaimo and Nicol, 2014; Mu et al., 2014). In addition, a previous study showed that activation of the CAMPPKA pathway increases excitability and enhances epileptiform activity in vitro (Boulton et al., 1993; Chang et al., 2010; Lee, 2015).

Epilepsy is a human brain disorder characterized by recurrent seizures. Epilepsy is a devastating neurological disease with a worldwide prevalence of 1-2\% (Hauser et al., 1993). Current therapies aim to control symptoms but are ineffective in the $20-30 \%$ of patients resistant to common antiepileptic drugs (AEDs) (French, 2007). Epilepsy is caused by many "insults," such as trauma, stroke, inflammation, and status epilepticus (SE) (Duncan et al., 2006). These "insults" lead to progressive changes in brain structure and function and an imbalance of excitatory and inhibitory pathways (Curia et al., 2008). Aberrant excitatory synapses may result in neuronal hyperexcitability and recurrent seizures (Scharfman, 2007). SE, as a brain insult, can induce "epileptogenesis" (Loscher and Brandt, 2010). SE and hyperexcitability of neurons must be minimized. However, the molecular mechanisms underlying the pathogenesis of SE and epilepsy are not clear.

Papaverine, an intrinsic inhibitor of PDE10A, has been reported to cause seizures (Carhuapoma et al., 2001; Kahramaner et al., 2014), and the cAMP-PKA pathway plays a role in neuronal excitability of neurons (Boulton et al., 1993; Chang et al., 2010; Lee, 2015). Based on these data, we hypothesized that the PDE10A inhibitor PF-2545920 plays an important role in SE.

\section{MATERIALS AND METHODS}

\section{Subjects and Ethics}

Adult male Sprague-Dawley (SD) rats from the Laboratory Animal Center of Chongqing Medical University weighing 200-230 g were used. Rats received water and food ad libitum and were maintained in a temperature-controlled, 12-h light/dark environment. Rats were randomly divided into experimental and control groups. All experiments were performed during the light phase, and the Chongqing Medical University Commission for Ethics of Experiments approved all procedures, which were conducted in accordance with international standards.

Twenty temporal neocortical samples from patients and ten control samples were randomly obtained from our human brain bank. Informed consent was obtained from patients and their lineal relatives. All protocols related to human subjects complied with the guidelines established by the Committee on Human Research at Chongqing Medical University and the National Institutes of Health. Detailed history, neurological examination, electroencephalogram (EEG) and neuroradiological studies were performed before surgery. Two or more neurologists diagnosed each patient, and the diagnosis of epilepsy was complied with the 1981 International Classification of Epileptic Seizures by the International League Against Epilepsy. All patients were refractory to maximal doses of three or more AEDs and required surgery. Normal temporal neocortex samples were obtained from patients diagnosed with brain trauma and no history of epilepsy or AEDs, who underwent neurosurgical intervention because of head trauma. Tables 1, 2 summarize the clinical features of temporal lobe epilepsy (TLE) patients and control subjects, respectively.

\section{Drugs}

2-((4-(1-Methyl-4-(pyridin-4-yl)-1H-pyrazol-3-yl) phenoxy) methyl) quinoline (PF-2545920, CAS NO: 1292799-56-4) was purchased from Selleck (Houston, TX, USA), dissolved in DMSO and diluted in $0.9 \%$ normal saline (NS). PF-2545920 or solvent control was administered intracerebroventricularly via a cannula (i.c.v., $0.02 \mu \mathrm{L} / \mathrm{min}, 10 \mu \mathrm{L}$ ) $30 \mathrm{~min}$ before behavior evaluation.

\section{Sample Preparation}

Rats were anesthetized fully and decapitated $2 \mathrm{~h}$ after behavioral studies. Half of the rat or human brain tissues were placed in liquid nitrogen for Western blotting, and the remaining tissue was embedded in $4 \%$ paraformaldehyde for immunofluorescence.

\section{Surgical Process}

The procedure used for intracerebroventricular cannulation and electrode implanting, with minor modifications, was described previously (Logrip et al., 2014; Xu et al., 2015) with minor modifications. Anesthetized rats were fixed in a stereotaxic apparatus (RWD Life Science, Co., Ltd, Shenzhen, China). The site of the left lateral ventricle was located using Paxinos and Watson: $\mathrm{AP}=1.0 \mathrm{~mm} ; \mathrm{ML}=1.5 \mathrm{~mm}$ on the left side; $\mathrm{DV}=3.5 \mathrm{~mm}$ from the dura. A microwire array $(\mathrm{a} 2 \times 8$ array 
TABLE 1 | Clinical characteristics of TLE patients.

\begin{tabular}{|c|c|c|c|c|c|c|}
\hline Patients & Age (y) & $\operatorname{Sex}(M / F)$ & Course (y) & AEDs before surgery & Pathology & Resection tissue \\
\hline 1 & 28 & M & 12 & CBZ, PHT, TPM & Gliosis & $\mathrm{TNr}$ \\
\hline 2 & 25 & $\mathrm{~F}$ & 10 & OXC, CBZ, VPA, PHT & Gliosis & $\mathrm{TNI}$ \\
\hline 3 & 33 & $\mathrm{~F}$ & 15 & LTG, TPM, PHT & $\mathrm{NL}$ & $\mathrm{TNI}$ \\
\hline 4 & 25 & $\mathrm{~F}$ & 11 & CBZ, LTG, TPM, PHT & Gliosis & $\mathrm{TNr}$ \\
\hline 5 & 20 & M & 13 & VPA, CBZ, PB, PHT, LEV & $\mathrm{NL}$ & $\mathrm{TNl}$ \\
\hline 6 & 30 & $\mathrm{~F}$ & 8 & CBZ, VPA, PB, TPM & Gliosis & $\mathrm{TNr}$ \\
\hline 7 & 21 & M & 11 & PB, CBZ, LEV, VPA, PHT & $\mathrm{NL}$ & $\mathrm{TNl}$ \\
\hline 8 & 23 & M & 10 & PHT, CBZ, PB, VPA & Gliosis & $\mathrm{TNI}$ \\
\hline 9 & 26 & M & 12 & CBZ, VPA, PB, TPM & $\mathrm{NL}$ & $\mathrm{TNI}$ \\
\hline 10 & 29 & M & 20 & CBZ, VPA, TPM, LEV & $\mathrm{NL}$ & $\mathrm{TNl}$ \\
\hline 11 & 47 & M & 23 & CBZ, VPA, PB, TPM, LTG & Gliosis & $\mathrm{TNI}$ \\
\hline 12 & 40 & $\mathrm{~F}$ & 30 & VPA, CBZ, PB, PHT & $\mathrm{NL}$ & $\mathrm{TNI}$ \\
\hline 13 & 19 & M & 7 & OXC, VPA, CBZ, PHT & $\mathrm{NL}$ & $\mathrm{TNl}$ \\
\hline 14 & 28 & $\mathrm{~F}$ & 12 & PHT, PB, VPA, LEV & NL, Gliosis & $\mathrm{TNr}$ \\
\hline 15 & 26 & M & 8 & VPA, CBZ, LEV, LTG & $\mathrm{NL}$ & $\mathrm{TNr}$ \\
\hline 16 & 29 & $\mathrm{~F}$ & 5 & PHT, TPM, LTG, VPA & $\mathrm{NL}$ & $\mathrm{TNl}$ \\
\hline 17 & 33 & $\mathrm{~F}$ & 7 & LEV, VPA, PHT & Gliosis & $\mathrm{TNr}$ \\
\hline 18 & 23 & M & 9 & PB, VPA, TPM, LEV, LTG & $\mathrm{NL}$ & $\mathrm{TNI}$ \\
\hline 19 & 30 & M & 20 & OXC, PB, CBZ, LEV & Gliosis & $\mathrm{TNI}$ \\
\hline 20 & 31 & $\mathrm{~F}$ & 15 & PB, VPA, PB, TPM, LEV & $\mathrm{NL}$ & $\mathrm{TNr}$ \\
\hline
\end{tabular}

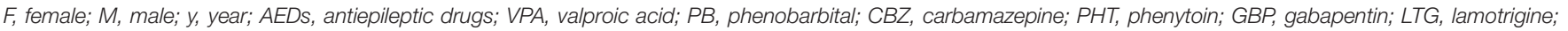
TPM, topamax; LEV, levetiracetam; OXC, oxcarbazepine; TN, temporal neocortex; I, left; $r$, right; NL, neuron loss.

of platinum-iridium alloy wire, each wire $25 \mu \mathrm{m}$ in diameter) was implanted into the right dorsal hippocampus (location: $\mathrm{AP}=3.6 \mathrm{~mm}, \mathrm{ML}=2.8 \mathrm{~mm}$, and $\mathrm{DV}=3.6 \mathrm{~mm}$ ). Two reference screws were implanted in the skull. All accessories were attached to the skull using cement. The following tests were performed 7 days after surgery and 3 days after environmental adaptation.

\section{Electrophysiology}

Local field potentials (LFPs) were filtered $(0.1-1000 \mathrm{~Hz}), 1000 \times$ amplified, and digitized at $4 \mathrm{kHz}$ using an OmniPlex ${ }^{\circledR} \mathrm{D}$ Neural Data Acquisition System (Plexon, Dallas, TX, USA), as described previously (Gong et al., 2009; Xu et al., 2015).

Two- to three-week-old male SD rats were used for patchclamp experiments. Coronal slices ( $380 \mu \mathrm{m}$ thick) were cut using

\begin{tabular}{lccccc}
\hline \multicolumn{7}{l}{ TABLE 2 } & \multicolumn{5}{l}{ Clinical characteristics of control patients. } \\
\hline Patients & $\begin{array}{c}\text { Age } \\
(\mathbf{y})\end{array}$ & $\begin{array}{c}\text { Sex } \\
\text { (M/F) }\end{array}$ & $\begin{array}{c}\text { Etiology } \\
\text { diagnosis }\end{array}$ & $\begin{array}{c}\text { Resection } \\
\text { tissue }\end{array}$ & Pathology \\
\hline 1 & 22 & $\mathrm{M}$ & Trauma & $\mathrm{TNI}$ & $\mathrm{N}$ \\
2 & 30 & $\mathrm{M}$ & Trauma & $\mathrm{TNr}$ & $\mathrm{N}$ \\
3 & 26 & $\mathrm{~F}$ & Trauma & $\mathrm{TNI}$ & $\mathrm{N}$ \\
4 & 21 & $\mathrm{~F}$ & Trauma & $\mathrm{TNr}$ & $\mathrm{N}$ \\
5 & 38 & $\mathrm{~F}$ & Trauma & $\mathrm{TNI}$ & $\mathrm{N}$ \\
6 & 31 & $\mathrm{M}$ & Trauma & $\mathrm{TNI}$ & $\mathrm{N}$ \\
7 & 25 & $\mathrm{M}$ & Trauma & $\mathrm{TNr}$ & $\mathrm{N}$ \\
8 & 22 & $\mathrm{M}$ & Trauma & $\mathrm{TNr}$ & $\mathrm{N}$ \\
9 & 35 & $\mathrm{~F}$ & Trauma & $\mathrm{TNl}$ & $\mathrm{N}$ \\
10 & 43 & $\mathrm{M}$ & Trauma & $\mathrm{TNr}$ & $\mathrm{N}$ \\
\hline
\end{tabular}

F, female; M, male; y, year; TN, temporal neocortex; I, left; r, right; N, normal. a vibratome (NVSLM1, Camden Instruments, Loughborough, $\mathrm{UK})$. Slices were cut at $2^{\circ} \mathrm{C}$ in a solution containing the following: $26 \mathrm{mM} \mathrm{NaHCO}, 22 \mathrm{mM}$ sucrose, $11 \mathrm{mM}$ glucose, $1 \mathrm{mM}$ $\mathrm{NaH}_{2} \mathrm{PO}_{4}, 3 \mathrm{mM} \mathrm{KCl}, 0.5 \mathrm{mM} \mathrm{CaCl}_{2}$, and $7 \mathrm{mM} \mathrm{MgCl}_{2}$ saturated with $95 \% \mathrm{O}_{2}$ and $5 \% \mathrm{CO}_{2}$. Slices recovered for $1 \mathrm{~h}$ at room temperature in artificial cerebral spinal fluid (ACSF) ( $\mathrm{pH} 7.4)$ : $1.25 \mathrm{mM} \mathrm{NaH}_{2} \mathrm{PO}_{4}, 124 \mathrm{mM} \mathrm{NaCl}, 3 \mathrm{mM} \mathrm{KCl}, 26 \mathrm{mM} \mathrm{NaHCO}_{3}$, $2.5 \mathrm{mM} \mathrm{CaCl}_{2}, 10 \mathrm{mM}$ glucose, and $1.3 \mathrm{mM} \mathrm{MgCl}_{2}$, saturated with $95 \% \mathrm{O}_{2}$ and $5 \% \mathrm{CO}_{2}$ (Tang et al., 2015).

Pyramidal neurons in the hippocampal CA1 area were chosen for recording using inverted phase contrast microscopy (Nikon, Japan). Slices were stabilized for at least 5 min prior to recording after patch rupture. Epileptic discharges were characterized by activity potentials that manifested as continuous high-frequency spike discharges compared with activity potential in $\mathrm{Mg}^{2+}$-ACSF (Sombati and Delorenzo, 1995). To measure action potentials (APs), glass pipettes were filled with an internal solution: $17.5 \mathrm{mM} \mathrm{KCl}, 0.5 \mathrm{mM}$ EGTA, $122.5 \mathrm{mM}$ K-gluconate, $10 \mathrm{mM}$ HEPES, and $4 \mathrm{mM}$ ATP, $\mathrm{pH}$ adjusted to 7.2 with $\mathrm{KOH}$. The bath solution was $\mathrm{Mg}^{2+}$-free ACSF with or without PF-2545920 $(5 \mu \mathrm{M})$ during recording. To measure miniature excitatory post-synaptic currents (mEPSCs), glass microelectrodes were filled with the following solution: $17.5 \mathrm{mM}$ CsCl, $10 \mathrm{mM}$ HEPES, $4 \mathrm{mM}$ ATP, $0.5 \mathrm{mM}$ EGTA, 132.5 mM Cs-gluconate, and 5 mM QX-314. Bicuculline $(10 \mu \mathrm{M})$ and tetrodotoxin $(1 \mu \mathrm{M})$ were added to the $\mathrm{Mg}^{2+}$-free ACSF to record mEPSCs. For recording the miniature inhibitory post-synaptic currents (mIPSCs), glass microelectrodes were filled with the following solution recordings $(\mathrm{pH} 7.2,275-$ $290 \mathrm{mOsm}$ ): $100 \mathrm{mM} \mathrm{CsCl}, 1 \mathrm{mM} \mathrm{MgCl}$, $1 \mathrm{mM}$ EGTA, $30 \mathrm{mM}$ $\mathrm{N}$-methyl-D-glucamine (NMG), 10 mM HEPES, 5 mM MgATP, 
$0.5 \mathrm{mM} \mathrm{Na} \mathrm{Na}_{2} \mathrm{GT}$ and $12 \mathrm{mM}$ phosphocreatine. Slices were submerged and continuously perfused with $\mathrm{Mg}^{2+}$-free ACSF containing 6,7-dinitroquinoxaline-2,3(1H,4H)-dione (DNQX, $20 \mu \mathrm{M}$ ), D-2-amino-5-phosphonovalerate (APV, $40 \mu \mathrm{M})$ and tetrodotoxin (TTX, $1 \mu \mathrm{M})$ with or without PF-2545920 $(5 \mu \mathrm{M})$. The membrane potential was maintained at $-70 \mathrm{mV}$ in voltageclamp mode.

Signals were acquired using a Multi Clamp 700B amplifier (Axon, Sunnyvale, CA, USA) and recorded using pClamp 9.2 software (Molecular Devices, Sunnyvale, CA, USA). All recordings were filtered at $2 \mathrm{kHz}$ and digitized at $10 \mathrm{kHz}$. Data were analyzed using Mini Analysis Software (Version 6.0.3; Synaptosoft, Decatur, GA, USA) and pClamp 9.2 software (Molecular Devices, Sunnyvale, CA, USA).

\section{Acute Rat Model of Seizures}

Extrahippocampal lesions and hippocampus-restricted injuries in human TLE are comparable to pilocarpine-induced rat models, which are useful for investigating human TLE (Bonilha et al., 2010). Lithium chloride (127 mg/kg, i.p., Sigma, USA) and atropine sulfate $(1 \mathrm{mg} / \mathrm{kg}$, i.p.) were administered $20 \mathrm{~h}$ and $30 \mathrm{~min}$ prior to pilocarpine administration $(30 \mathrm{mg} / \mathrm{kg}$, i.p., Sigma), respectively. Diazepam $(10 \mathrm{mg} / \mathrm{kg}$, i.p.) was administered after 90 min of SE to terminate the convulsive seizures. Seizure activities were scored according to Racine's standard criteria (Racine, 1972). Rats in the experimental group successfully kindled (levels 4 or more) and were considered the SE group. The control group was composed of rats that were not successfully kindled (levels $<4$ ) and are the non-SE group. Electrographic seizure was defined as high frequency $(>5 \mathrm{~Hz})$, high amplitude ( $>2 \times$ baseline) and lasting more than $5 \mathrm{~s}$ (Palencia et al., 2012).

\section{Subcellular Fraction Preparation and Western Blot}

Hippocampal tissue for subcellular fraction collection was collected $2 \mathrm{~h}$ after SE termination. The tissue was homogenized in ice-cold Tris- $\mathrm{HCl}$ buffer $(30 \mathrm{mM}, \mathrm{pH}$ 7.4) containing $4 \mathrm{mM}$ EDTA, $1 \mathrm{mM}$ EGTA, $5 \mathrm{mM} \mathrm{Na} \mathrm{P}_{2} \mathrm{O}_{7}, 1 \mathrm{mM} \mathrm{Na} \mathrm{VO}_{4}$, $100 \mu \mathrm{M}(\mathrm{NH} 4)_{6} \mathrm{MO}_{7} \mathrm{O}_{24}, 25 \mathrm{mM}$ NaF, protease inhibitors (Roche Applied Science) and phosphatase inhibitors (Sigma-Aldrich). Homogenates were centrifuged at $700 \mathrm{~g}$ for $7 \mathrm{~min}$ at $4^{\circ} \mathrm{C}$, and the supernatants were collected. Pellets were re-suspended and centrifuged at $4^{\circ} \mathrm{C}$ at $700 \mathrm{~g}$ for another $7 \mathrm{~min}$. One portion of supernatants was collected as total homogenates, and other supernatants were centrifuged at $100,000 \mathrm{~g}$ for $1 \mathrm{~h}$ at $4^{\circ} \mathrm{C}$. Pellets were re-suspended in the same buffer containing $0.5 \%$ Triton $\mathrm{X}-100$ and incubated for $30 \mathrm{~min}$ at $4^{\circ} \mathrm{C}$. The suspensions were layered on sucrose $(1 \mathrm{M})$ and centrifuged at $100,000 \times g$ for $1 \mathrm{~h}$ at $4^{\circ} \mathrm{C}$. Triton-insoluble material (highly enriched in postsynaptic densities) sedimented through the sucrose layer and was re-suspended in the same buffer containing 1\% SDS, then stored at $-80^{\circ} \mathrm{C}$ (Dong et al., 2015; Zhang et al., 2016).

The same sample amounts $(50 \mu \mathrm{g}$ for total protein and $10 \mu \mathrm{g}$ for subcellular fractions) were separated using $10 \%$ SDS-PAGE gels and transferred onto PVDF membranes. The membranes were blocked with $5 \%$ non-fat milk for $1 \mathrm{~h}$ at room temperature and blotted with the following primary antibodies: PDE10A (1:200, Santa Cruz, CA, USA), GluA1 (1:3000, Abcam), GluA2 (1:1000, Abcam), NR1 (1:3000, Abcam), NR2A (1:1000, Millipore), NR2B (1:1000, Millipore), PSD95 (1:500, Millipore), GABRA1 (1:500, Proteintech), p-GluA1 (Ser845, 1:1000, Abcam), CaMKII (1:1000, Abcam) and $\beta$-actin (1:5000, Abcam) overnight at $4^{\circ} \mathrm{C}$. The blots were incubated with an HRPconjugated goat anti-mouse or anti-rabbit antibody (1:3000) for $1 \mathrm{~h}$ at room temperature. The Enhanced Chemiluminescence Detection System (Amersham ECL) and Bio-Rad ChemiDoc XRS+ system were used for blot detection and analyses, respectively. Densitometry quantitation was performed using Quantity One Software (Bio-Rad Laboratories, Hercules, CA, USA). Total proteins were normalized to $\beta$-actin, and proteins from subcellular fractions were normalized to the same protein in total proteins.

\section{Immunofluorescence}

Tissue sections $(10 \mu \mathrm{m})$ were incubated in normal goat serum (Zhongshan Golden Bridge, Beijing, China) for $30 \mathrm{~min}$ followed by incubation with a mixture containing a PDE10A antibody (rabbit polyclonal antibody, 1:100), a microtubuleassociated protein 2 (MAP2) antibody (chicken polyclonal antibody, 1:100, Zhongshan Golden Bridge) and a glial fibrillary acidic protein (GFAP) antibody (mouse polyclonal antibody, 1:100, Zhongshan Golden Bridge) overnight at $4^{\circ} \mathrm{C}$. Sections were washed twice in PBS and incubated with a mixture of DyLight 488-conjugated goat anti-rabbit IgG (1:200, Zhongshan Golden Bridge), DyLight 549-conjugated goat anti-mouse IgG (1:200, Zhongshan Golden Bridge) and DyLight 405-conjugated goat anti-chicken IgG (1:200, Zhongshan Golden Bridge) in a darkroom for $90 \mathrm{~min}$ at $37^{\circ} \mathrm{C}$. Tissue sections were mounted in 50\% glycerol/PBS. Fluorescence was detected using laser scanning confocal microscopy (Leica Microsystems Heidelberg $\mathrm{GmbH}$, Germany) on an Olympus IX 70 inverted microscope (Olympus, Japan) equipped with a Fluoview FVX confocal scan head. To determine the specificity of antibodies, PDE10A antibody (488 channel), GFAP antibody (549 channel) and microtubule-associated protein 2 (MAP2) antibody (405 channel) were replaced by PBS with the same protocols.

\section{Statistical Analysis}

The data are presented as means \pm SEM. Samples in each experiment were analyzed in triplicate. One-way ANOVA was used to compare data from more than two groups (SPSS 19.0). Paired-samples or independent-samples Student's $t$-test were used for comparing two groups where appropriate. The $\chi^{2}$ test was used to compare gender differences between TLE patients and controls. $P<0.05$ indicated statistical significance.

\section{RESULTS}

\section{Clinical Characteristics of Human Subjects}

The 20 patients ( 9 females, 11 males) in the TLE group had a mean age of $28.3 \pm 1.489$ years and an average disease 
course of $12.9 \pm 1.382$ years. The 10 cases (four females and six males) in the control group had a mean age of $29.3 \pm 2.367$ years. There were no significant differences in age or sex between the TLE group and control group $(P>0.05)$.

\section{PDE10A Expression in the Hippocampus and Cortex of the Rat Model}

Triple-labeled immunofluorescence staining revealed that PDE10A (green) and MAP2 (blue) were co-expressed in neurons in the hippocampus and cortex of rat models but not with GFAP (red) in astrocytes (Figure 1A). We also examined the levels of PDE10A protein in the hippocampus and cortex of rat models at different time points after SE using Western blotting to confirm PDE10A expression in our animal model. PDE10A expression increased in the hippocampus (Figure 1B, NSE: $0.148 \pm 0.025$, PSE-6 h: $0.137 \pm 0.019$, PSE- 24 h: $0.217 \pm 0.022$, PSE-72 h: $0.224 \pm 0.061 ; n=5, P>0.05$ ) and cortex (Figure 1C, NSE: $0.174 \pm 0.015$, PSE-6 h: $0.203 \pm 0.015$, PSE-24 h: $0.18 \pm 0.023$, PSE-72 h: $0.198 \pm 0.025 ; n=5, P>0.05)$, but not significantly. The control group was composed of rats that were not successfully kindled (levels $<4$ ) and recorded as the non-SE group.

\section{PDE10A Expression in the Neocortex of TLE Patients}

Data from our animal studies suggested that PDE10A is involved in the acute seizure model; therefore, we hypothesized that it may play a role in epilepsy patients. We examined PDE10A expression using Western blotting and immunofluorescence. Immunofluorescence staining demonstrated that PDE10A (green) and MAP2 (blue) are co-expressed in neurons in the neocortex of TLE patients but not with GFAP (red) in astrocytes (Figure 2A). Negative control for all channels was shown in the (Supplementary Material Figure S1). We performed Western blotting to examine alternations in PDE10A expression in human sections. PDE10A expression increased significantly in TLE patients compared with control groups $(P<0.05)$ (Figure 2B).

\section{Effect of PF-2545920 on Epileptiform Discharge and Epileptic Seizure}

We performed behavioral and LFP studies to examine whether the administration of PF-2545920 alone induced spontaneous seizures and epileptiform discharge. Vehicle or PF-2545920 $(50 \mu \mathrm{M})$ was administrated and animals were monitored for 6 h (10 $\mu$ L, i.c.v., $n=5)$. Vehicle or PF-2545920 alone did not induce spontaneous seizures or epileptic discharges or any other abnormalities (Figures 3A,C). We administered PF-2545920 once (50 $\mu \mathrm{M}, 10 \mu \mathrm{L}$, intracerebroventricularly) (PF-50) prior to pilocarpine application to examine the role of PF-2545920 in the progression of epileptic seizure. The latency time was significantly shortened in the PF-50 group compared with the vehicle group (Figure 3E, $1683.33 \pm 118.91$ s, $n=9$ vs. $2703.13 \pm 367.28$ s, $n=8 ; P<0.05)$. The cumulative time was significantly increased in the PF-50 group compared with
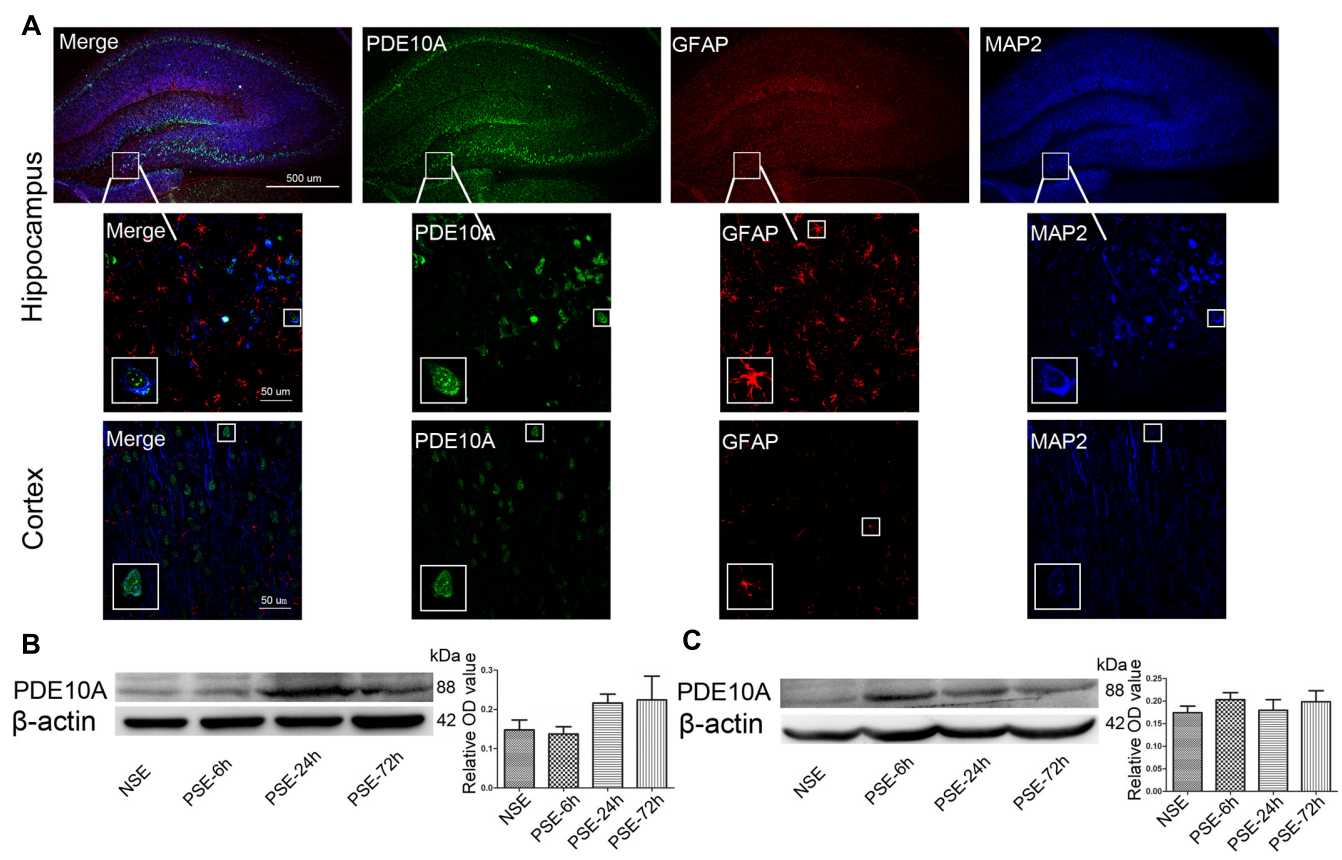

FIGURE 1 | PDE10A expression in the hippocampus and cortex of rats. (A) Triple-label immunofluorescence demonstrated that PDE10A (green) and GFAP (red) were not co-expressed in astrocytes, but PDE10A (green) and MAP2 (blue) were co-expressed in neurons ( $n=5$ ). The white squares indicate positive cells in the cortex or hippocampus of rats. Representative Western blot images of hippocampus (B) and cortex (C) of rats at different time points post-status epilepticus. PDE10A increased after SE with a trend, but not significantly (non-SE; $6 \mathrm{~h}$ post-SE, PSE-6; $24 \mathrm{~h}$ post-SE, PSE-24; $72 \mathrm{~h}$ post-SE, PSE-72; $n=5, P>0.05$ ). 

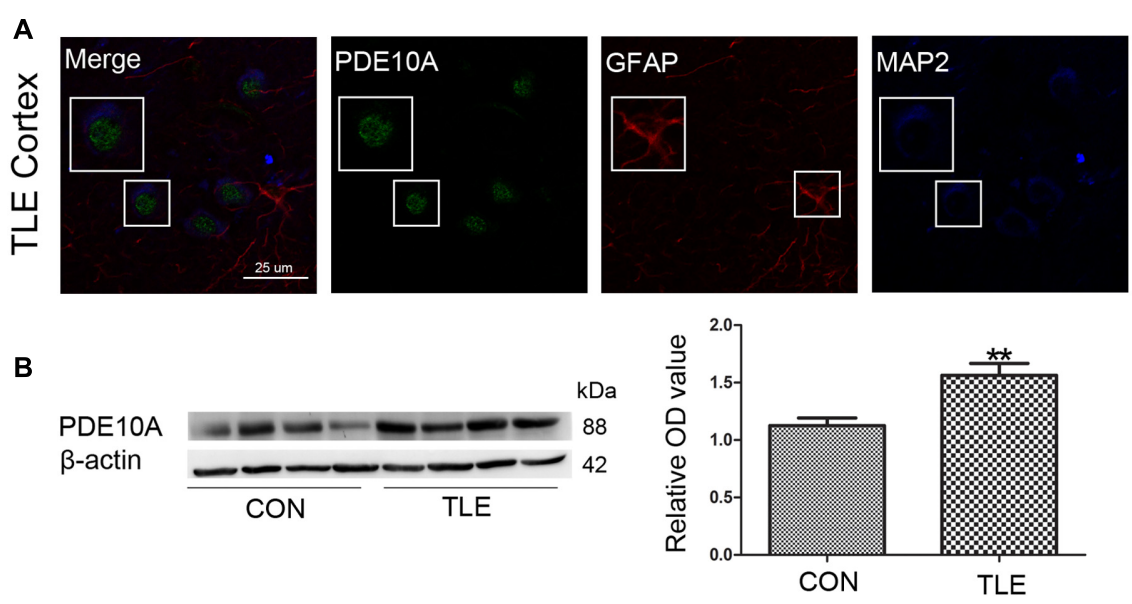

FIGURE 2 | PDE10A expression in the temporal cortex of TLE patients. (A) Triple-label immunofluorescence demonstrated that PDE10A (green) and GFAP (red) were not co-expressed in astrocytes, but PDE10A (green) and MAP2 (blue) were co-expressed in the neurons of patient cortex ( $n=10$ ). The white squares indicate positive cells. (B) Representative Western blots revealed PDE10A expression in TLE patients and controls. The mean OD ratio of PDE10A relative to $\beta$-actin was significantly higher in the TLE group compared with the control group (** $P<0.01)$.

the vehicle group (Figure $3 \mathrm{~F}, 2757 \pm 109.86$ s, $n=9$ vs. $1734.38 \pm 321.91 \mathrm{~s}, n=8 ; P<0.05)$.

Status epilepticus is characterized by convulsions and the synchronized discharges of a population of neurons. Therefore, we used in vivo LFP recording to confirm the effect of PF-50 on LFP. PF-50 treatment dramatically shortened the latency to full electrographic SE (Figure 3G, $1619.22 \pm 117.82$ s, $n=9$ vs. $2650.13 \pm 369.68 \mathrm{~s}, n=8 ; P<0.05$ ). Figures 3B,D show the typical figures of LFP after pilocarpine with (Figure 3D) or without (Figure 3B) PF-50. Using the same protocol, we investigated the effect of different concentrations of PF-2545920 on SE. There was no significant difference in latency time between the vehicle group and PF group at $10 \mu \mathrm{M}$. However, there was a significant difference between groups treated with PF-50 $\mu \mathrm{M}$ or PF-100 $\mu \mathrm{M}$ compared with the vehicle group (Figure 3H, $P<0.01$ ). These results indicate that PF-2545920 exhibits proconvulsant effects in a dose-dependent manner with a ceiling effect.

\section{PF-2545920 Induced Neuronal Hyperexcitability}

We used whole cell patch-clamp electrophysiology on CA1 pyramidal neurons in rat hippocampal slices perfused with $\mathrm{Mg}^{2+}$-free ACSF to further evaluate the role of PF-2545920 in the hippocampus and verify observations from the behavioral tests. Figure $4 \mathrm{~A}$ show the typical features of APs, mEPSCs, and mIPSCs, respectively, in pyramidal neurons before or after perfusion with PF-2545920 (5 $\mu \mathrm{M})$. The frequency of APs from pyramidal neurons after PF-2545920 $(5 \mu \mathrm{M})$ perfusion increased significantly compared with the frequency immediately prior to perfusion with $\mathrm{Mg}^{2+}$-free ACSF (Figure 4B, $4.26 \pm 1.19 \mathrm{~Hz}$ vs. $1.86 \pm 0.39 \mathrm{~Hz} ; n=10, P<0.05)$. To determine whether the imbalance of excitatory and inhibitory transmission may cause neuronal hyperexcitability, we recorded mEPSCs and
mIPSCs. Brain slices perfused with PF-2545920 demonstrated a significant increase in the frequency of mEPSCs (Figure 4C, $5.92 \pm 1.45 \mathrm{~Hz}$ vs. $1.50 \pm 0.64 \mathrm{~Hz} ; n=10, P<0.05)$. No significant differences between groups were found in the amplitude of mEPSCs (Figure 4D) or the frequency (Figure 4E) or amplitude of mIPSCs (Figure 4F). The corresponding cumulative fraction of mEPSCs or mIPSCs confirmed our results. There was no significant difference in the frequency of AP or the frequency or amplitude of mEPSCs and mIPSCs prior to perfusion or after washout (Figure 4A, $n=10$, $P>0.05)$. The electrophysiological data were consistent with and confirmed the findings of our animal behavior study.

\section{GluA1 and NR2A Levels Increased in PSD}

Total and synaptic NMDAR, AMPAR, and GABAR subunit compositions are not static but change dynamically in response to a variety of neuronal activity, including SE (Rajasekaran et al., 2013; Loddenkemper et al., 2014). Activity dynamically regulates the functional multiprotein units of the PSD via local protein turnover (Ehlers, 2003). Imbalance between inhibition and excitation is one of the main causes of seizures (Scharfman, 2007). We investigated the total (Figure 5A) and synaptic (Figure 5B) expression levels of the main subunits of AMPAR (GluA1 and GluA2), NMDAR (NR1, NR2A, and NR2B) and GABARA1 to delineate the molecular mechanisms linking the inhibition of PDE10A to the imbalance of excitatory and inhibitory transmission. We compared subunit expression between vehicletreated rats with SE (V-SE group), vehicle-treated rats without SE (V-non-SE group), PF-50-treated rats with SE (PF-SE group), and PF-50-treated rats without SE (PF-non-SE group) in total lysates and their synaptic/total ratio $(n=5$ in each group, one-way ANOVA followed by LSD tests). In total protein homogenates, the data showed that PF-2545920 did not affect the levels of GluA1 (V-SE group: $0.7 \pm 0.089$ vs. PF-SE group: 

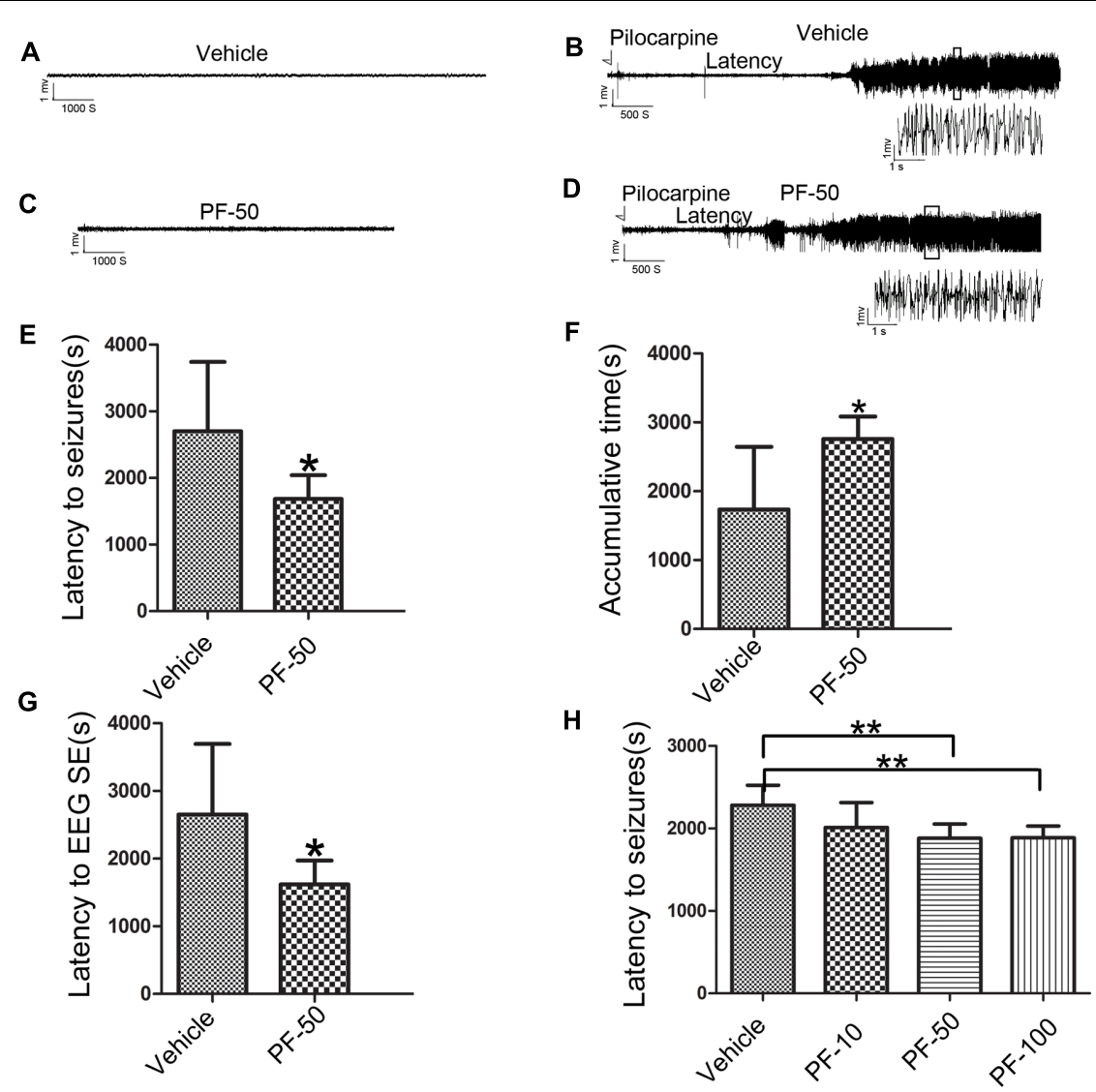

FIGURE 3 | Effect of PF-2545920 on epileptic seizure. (A) Representative figure of LFP under the treatment of vehicle alone. (B) Representative recordings of Licl-Pilocarpine-induced status epilepticus in the vehicle group. (C) Representative figure of LFP under PF-2545920 treatment (50 $\mu \mathrm{M}, 10 \mu \mathrm{L}$, i.c.v., PF-50). (D) Representative recordings of Licl-Pilocarpine-induced status epilepticus after PF-2545920 administration (50 $\mu \mathrm{M}, 10 \mu \mathrm{L}$, i.c.v., PF-50). (E) Behavioral evaluation revealed that the latency time in the PF-2545920-treated group was significantly decreased compared with the vehicle-treated group $(50 \mu \mathrm{M}, 10 \mu \mathrm{L}$, i.c.v., PF-50; $\left.n=8-9,{ }^{*} P<0.05\right)$. (F) Behavioral evaluation demonstrated that the cumulative time of generalized tonic clonic seizures in PF-2545920-treated group increased significantly compared with the vehicle-treated group $\left(50 \mu \mathrm{M}, 10 \mu \mathrm{L}\right.$, i.c.v., PF-50; $\left.n=8-9,{ }^{*} P<0.05\right)$. (G) EEG evaluation of latency time to full electrographic SE in PF-2545920-treated group was statistically decreased compared with the vehicle-treated group (50 $\mu \mathrm{M}, 10 \mu \mathrm{L}$, i.c.v., PF-50; $n=8-9, * P<0.05)$. (H) Behavioral evaluation demonstrated that latency time in PF-2545920-treated groups at 50 and $100 \mu \mathrm{M}$ were statistically decreased compared with the vehicle-treated group (10 $\mu \mathrm{M}, 10 \mu \mathrm{L}, \mathrm{PF}-10 ; 50 \mu \mathrm{M}, 10 \mu \mathrm{L}, \mathrm{PF}-50 ; 100 \mu \mathrm{M}, 10 \mu \mathrm{L}, \mathrm{PF}-100 ; n=7, * * P<0.01)$.

$0.486 \pm 0.086, P>0.05$; V-non-SE group: $0.4 \pm 0.072$ vs. PF-non-SE group: $0.196 \pm 0.028, P>0.05$, Figure 5C). However, seizures increased the expression of GluAl (V-SE: $0.7 \pm 0.089$ vs. V-non-SE: $0.4 \pm 0.072$; PF-SE: $0.486 \pm 0.086$ vs. PF-non-SE: $0.196 \pm 0.028, P<0.05)$. Unexpectedly, PF-2540920 increased the synaptic/total ratio significantly (V-SE: $0.543 \pm 0.08$ vs. PF-SE: $0.799 \pm 0.079$; V-non-SE: $0.292 \pm 0.037$ vs.PF-non-SE: $0.742 \pm 0.045, P<0.05$, Figure 5D). These results indicate that PF-2545920 induced the redistribution of GluA1 to postsynaptic densities. Notably, GluA2 expression was not altered in total lysates (Figure 5E) or the synaptic/total ratio (Figure 5F, $P>0.05)$. The levels of other proteins involved in synaptic function, including NMDA receptor subunits NR1, NR2A, and NR2B, were not altered after PF-2545920 treatment in total lysates (Figures 5G,I,K). No significant differences in the synaptic/total ratio of $\mathrm{NR} 1$ and $\mathrm{NR} 2 \mathrm{~B}$ were found related to the effect of PF-2545920 (Figures 5H,L). However, NR2A was significantly increased in the synaptic/total ratio after PF-2545920 treatment in groups without SE (Figure 5J). The results of the total lysis suggest that PF-2545920 affected the distribution of NR2A in the PSD. The primary subunit of GABARs, GABARA1, was also investigated in homogenates and subcellular fractions. Although the overall levels of GABARA1 were reduced after SE, PF-2545920 did not alter the distribution of GABARA1 (Figures 5M,N), which was consistent with our findings using whole cell patch-clamp. These data demonstrated significant alterations in GluA1 and NR2A in the subcellular fractions, further supporting our electrophysiological data and correlating, in part, with our behavioral data.

\section{p-GluA1 and CaMKII Expression in Rat Hippocampus}

PF-2545920 affects the phosphorylation of GluA1 at Ser845 ( $p$-GluA1Ser845) (Grauer et al., 2009). Our study demonstrated that the ratio of $p$-GluA1Ser845/GluA1 in PF-SE was significantly 


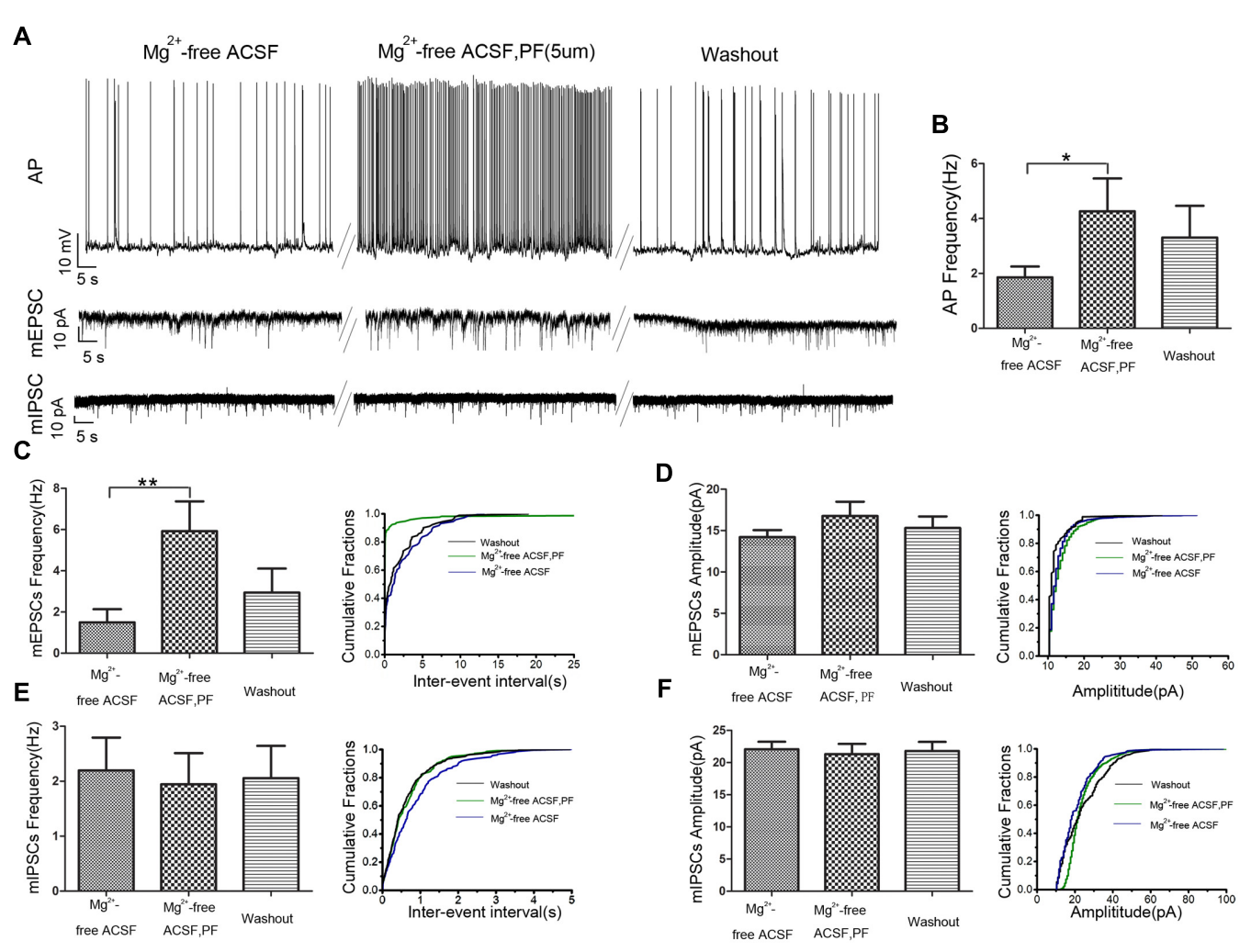

FIGURE 4 | PF-2545920 increases the excitability of pyramidal neurons in the CA1 region. (A) Representative traces of action potentials (APs), mEPSCs, mIPSCs before and after the perfusion of PF-2545920. (B) Frequency of APs increased significantly in pyramidal neurons after perfusion of PF-2545920 (data are means \pm SEM, $n=10, * P<0.05$ ). (C) Frequency of mEPSC increased significantly after PF-2545920 perfusion (data are means \pm SEM, $n=10, * * P<0.01)$, and its representative cumulative fractions. (D) Amplitude of mEPSC was not altered after PF-2545920 treatment (data are means \pm SEM, $n=10, P>0.05$ ), and its representative cumulative fractions. (E) Data demonstrated no significant difference in the frequency of mIPSCs after PF-2545920 treatment (data are means \pm SEM, $n=10, P>0.05)$, and its representative cumulative fractions. (F) Data revealed no significant difference in the amplitude of mIPSC after PF-2545920 treatment (data are means \pm SEM, $n=10, P>0.05$ ), and its representative cumulative fractions.

higher than the V-SE group (Figure 6A, $1.135 \pm 0.126$ vs. $0.679 \pm 0.022 ; n=5, P<0.05)$. Previous studies have demonstrated that CaMKII participates in the synaptic modification of synaptic receptors (NMDARs, AMPARs). Our data revealed that PF-2545920 downregulated CaMKII expression compared with the non-SE groups (Figure 6B, $0.588 \pm 0.073$ vs. $0.93 \pm 0.167 ; n=5, P<0.05)$.

\section{DISCUSSION}

We present the following results in this work: (i) PF2545920 exerted proconvulsant effects; (ii) PF-2545920 induced hyperexcitability of pyramidal neurons in CA1; (iii) PF-2545920 redistributed GluA1 and $\mathrm{NR} 2 \mathrm{~A}$ to the PSD; (iv) PDE10A expression increased significantly in TLE patients; and (v) PF-2545920 upregulated the $p$-GluA1Ser845/GluA1 ratio.

Our data suggest that PDE10A expression was upregulated in the cortex of patients with epilepsy. The exact role of upregulated PDE10A in TLE patients is unknown. We found that PDE10A was primarily located in neurons in our experimental rat model and in human patients, which is consistent with a previous study (Seeger et al., 2003). However, the hippocampus is the most widely studied brain region in human and experimental epilepsy (Thom, 2014). Electrophysiology experiments were performed to examine the effect of PF-2545920 on neuronal hyperexcitability, revealing that PF-2545920 increased excitatory, but not inhibitory, synaptic transmission. This imbalance of excitatory and inhibitory conductance may lead to the proconvulsant effects of PF-2545920, consistent with a previous study (Scharfman, 2007).

Synapse formation is essential for the physiology and pathology of neuronal circuitry in the brain, and its impairment is a primary cause of epilepsy (Sutula et al., 1988; Rakhade and Jensen, 2009). The PSD, which contains receptors and signaling proteins, is the primary structure underlying synaptic plasticity (Scannevin and Huganir, 2000). Accumulating evidence reveals that synaptic NMDAR, AMPAR, and GABAR are not static but change dynamically in response to neuronal activity. These changes contribute to neuropsychiatric disorders when the balance is disturbed under pathological conditions (Lau and Zukin, 2007). Russwurm et al. (2015) found that in the striatum, PDE10A acts as a post-synaptic signaling element and is co-immunoprecipitated with PSD95 and NMDA 


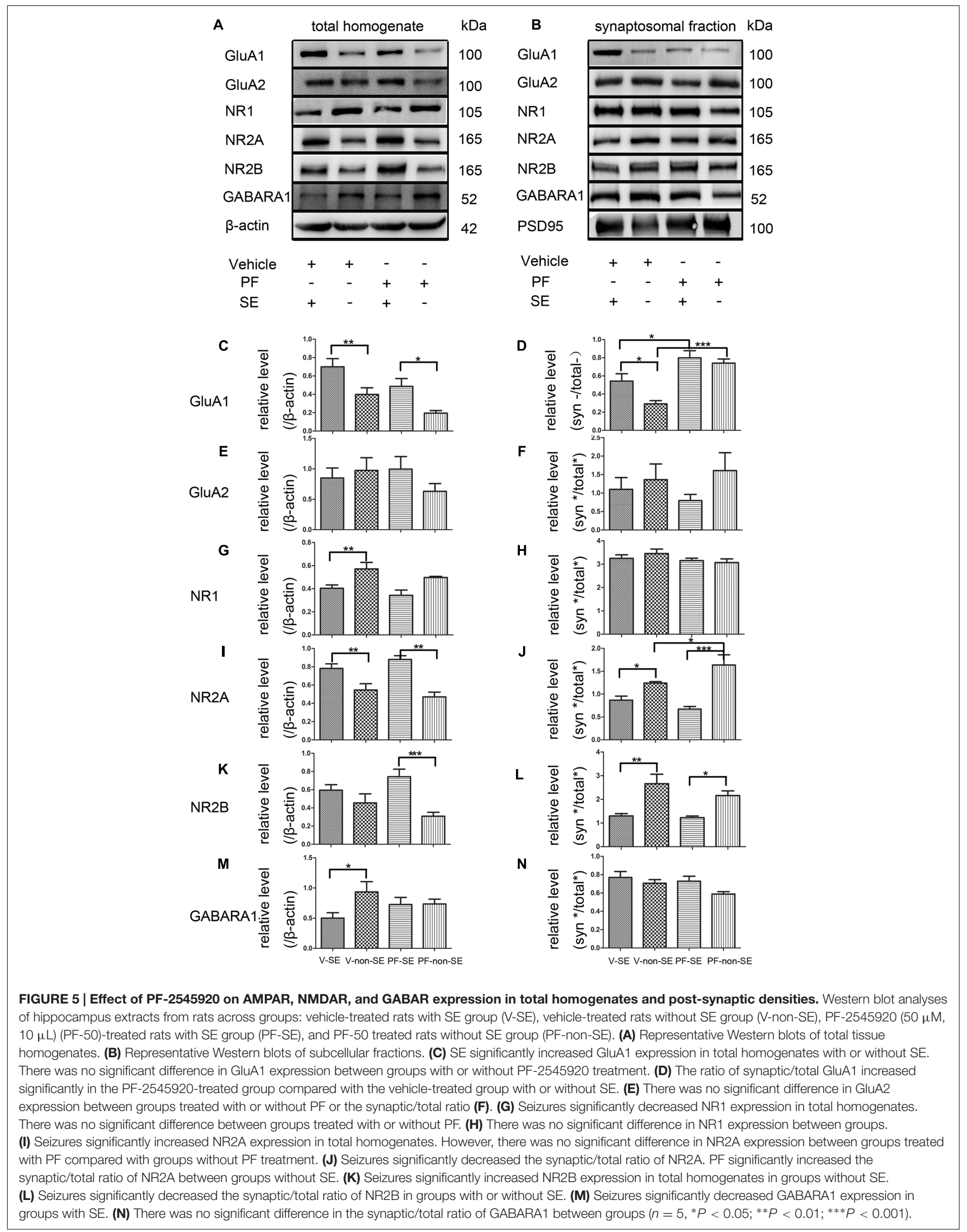



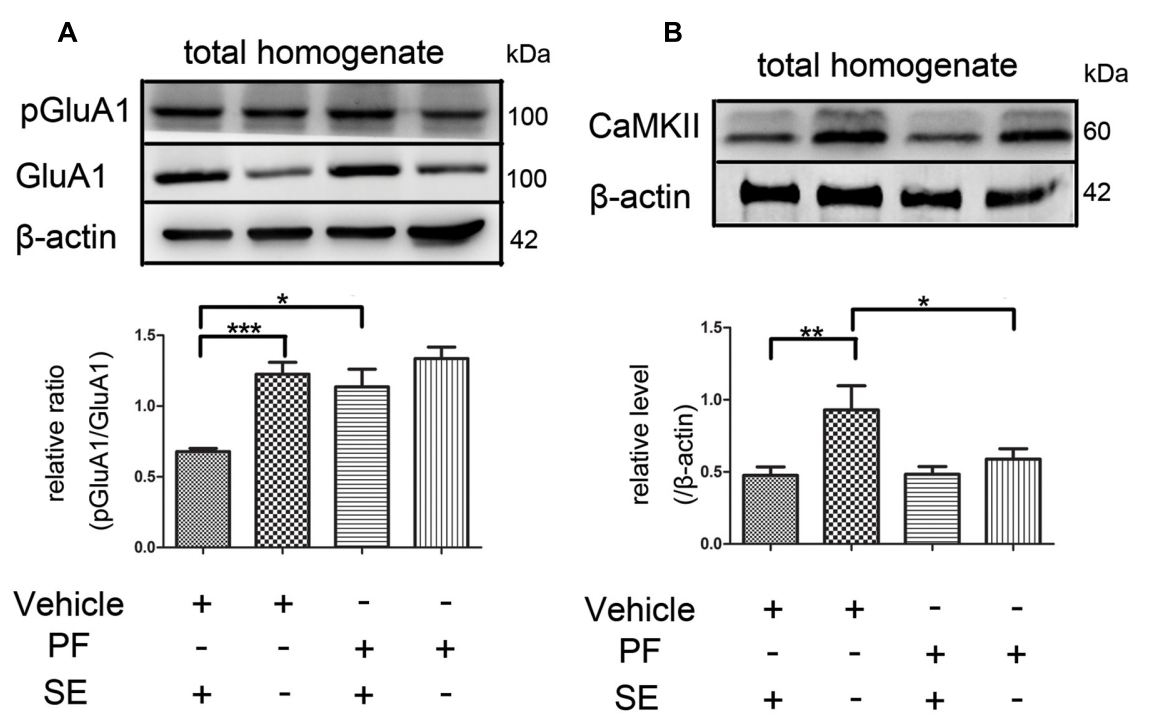

FIGURE 6 | The $\boldsymbol{p}$-GluA1Ser845/GluA1 ratio and CaMKII in rat hippocampus. (A) Representative Western blot shows that seizures significantly decreased the ratios of $p$-GluA1Ser845 relative to GluA1 in total homogenates. PF significantly increased the ratios of $p$-GluA1Ser845 relative to GluA1 in groups with SE ( $n=5$, $\left.{ }^{*} P<0.05 ;{ }^{* * *} P<0.001\right)$. (B) Representative Western blot shows that seizures significantly decreased the expression of CaMKII in total homogenates. PF significantly decreased the expression of CaMKII in groups without SE $\left(n=5,{ }^{*} P<0.05 ; * * P<0.01\right)$.

receptor subunits. Notably, biochemical data showed that GluA1 and NR2A were trafficked to the PSD after PF-2545920 treatment and electrophysiological data showed an increase of mEPSCs. We combined biochemical and electrophysiological research methods because the biochemical results allowed us to identify specific changes in the receptor while the electrophysiological data provided the direct evidence of neuronal hyperexcitability. There was no significant difference in GluA2 levels among the treatment and control groups. This result is somewhat surprising because it has been suggested that increased levels of synaptic GluA2 homomeric AMPAR are important for SE (Rajasekaran et al., 2012). The exact mechanisms are not clear, but a growing body of evidence has convincingly demonstrated that AMPARs lacking GluA2 exhibit distinct biophysical characteristics, including greater conductance, calcium permeability, and inwardly rectifying currents (Zaccara et al., 2013). A prior study demonstrated that the selective activation of NR2A-containing NMDARs increases BDNF gene expression, which contributes to the development of epilepsy (Chen et al., 2007). However, SE in rats or patients affects the surface expression of GluA1 and NR2A or other subunits (Rajasekaran et al., 2013; Loddenkemper et al., 2014). Therefore, the aberrant trafficking of GluA1- and NR2A-containing receptors may be attributable to SE or/and PF-2545920. Data from our biochemical and behavioral experiments suggest that the proconvulsant effects are attributable to the redistribution of GluA1- and NR2A-containing receptors mediated by PF2545920 .

GluA1 contains phosphorylation sites for CaMKII, PKC and PKA, which regulate its synaptic insertion (Anggono and Huganir, 2012). We examined p-GluA1 expression to uncover the mechanism regulating redistribution of GluA1.
Our experiments demonstrated a significant increase in p-GluA1Ser845 after PF-2545920 treatment. This result is consistent with a previous study demonstrating that a PDE10A inhibitor regulated the phosphorylation state of presynaptic- or post-synaptic-associated complexes (Nishi et al., 2008). Notably, GluA1 phosphorylation may participate in neurotransmitter transmission and strengthening of seizure activity via the potentiation of currents induced through AMPA receptors (Benke et al., 1998; Derkach et al., 1999). CaMKII is a postsynaptic protein involved in synaptic modification, and it is critically required for the synaptic recruitment of AMPARs and NMDARs (Opazo et al., 2010). In addition, Opazo et al. (2010) showed that exocytosis and/or trapping of AMPAR-containing vesicles to the PSD in activated synapses may be regulated in a CaMKII-dependent manner. The expression of CaMKII was downregulated, which suggests that CaMKII does not play an important role in the phosphorylation of the GluA1 subunit after PF-2545920 treatment. However, the downregulation of CaMKII might prevent GluA1 redistribution to the PSD. These findings suggest that $p$-GluA1Ser845 participates in the redistribution of GluA1 via the cAMP/PKA signaling pathway. Russwurm et al. (2015) found that in the striatum, PDE10A is co-immunoprecipitated with PSD95 and NMDA receptor subunits. Further studies are necessary to reveal the exact trafficking mechanism of NR2A in our study. However, NMDARs in the PSD differ in their subunit compositions and are differentially regulated in response to changes in phosphorylation (Barria and Malinow, 2002); further studies is required. Previous study showed that PF-2545920 upregulates cAMP concentration (Siuciak et al., 2006; Grauer et al., 2009; Liddie et al., 2012), while cAMP modulate epileptiform after discharge generation in rat hippocampal slices (Higashima et al., 2002). Our data showed 
PF-2545920 enhances the excitability of pyramidal neurons and seizure activity possibly via activation of the cAMP-PKA pathway.

Status epilepticus is a life-threatening form of seizure activity that represents a major medical emergency associated with significant morbidity and mortality (Chen and Wasterlain, 2006). Preclinical studies have recently investigated PF-2545920 as candidate drug. Volunteers participating in early clinical trials rarely experience serious injuries, but these events are very severe when they do occur (Bass et al., 2004). Therefore, it is essential to identify any proconvulsant activity for drugs being studied (Porsolt et al., 2002). Additional studies should be performed to characterize the physiological, pharmacological, and behavioral actions of PF-2545920 in humans and other species exposed to this drug. The upregulation of PDE10A in TLE patients and the trend of upregulation in rats after SE compared with controls (trauma patients or rats that were not successfully kindled) might modulate or decrease seizures. There are some limitations in our study. While no significant alterations to GluA2-containing receptors were detected, we cannot exclude the involvement of GluA2-containing AMPARs in PF-2545920-mediated proconvulsant functions or NR1 and NR2B. Ethical limitations preclude the absolute acquisition of absolutely normal brain tissues and human hippocampus for investigation. Recently, Harada et al. (2017) found an inhibitor targeting PDE10A, which suppressed seizure frequency. Although, the precise reasons for this discrepancy remain unclear, there are some possibilities: (i) The animal model used in their work, "R6/2 mouse model of Huntington's disease," has a background of neurodegeneration and spontaneous seizures under stress. In contrast our animal model is a healthy rat injected with pilocarpine to initiate SE. (ii) Their study, which shows that repeated treatment with TAK-063 prevents striatal neurodegeneration, is focused on the mechanism by which TAK-063 blocks the reduction of BDNF levels. Our study showed that PF-2545920 enhances the excitability of pyramidal neurons and seizure activity possibly via activation of the cAMP-PKA pathway (Boulton et al., 1993; Chang et al., 2010; Lee, 2015). (iii) TAK-063, which has a faster off-rate, induces similar levels of activation in medium spiny neurons (MSNs) in the indirect pathway, while MSNs in the direct pathway are only partially activated (Suzuki et al., 2016). The role of TAK-603 in the hippocampus may differ from PF-2545920. If so, TAK-063 is a better choice for neurological disease and should be studied further.

\section{REFERENCES}

Ahmad, R., Bourgeois, S., Postnov, A., Schmidt, M. E., Bormans, G., Van Laere, K., et al. (2014). PET imaging shows loss of striatal PDE10A in patients with Huntington disease. Neurology 82, 279-281. doi: 10.1212/WNL. 0000000000000037

Anggono, V., and Huganir, R. L. (2012). Regulation of AMPA receptor trafficking and synaptic plasticity. Curr. Opin. Neurobiol. 22, 461-469. doi: 10.1016/j.conb. 2011.12.006

Averaimo, S., and Nicol, X. (2014). Intermingled cAMP, cGMP and calcium spatiotemporal dynamics in developing neuronal circuits. Front. Cell Neurosci. 8:376. doi: 10.3389/fncel.2014.00376

\section{CONCLUSION}

Our study revealed that PF-2545920 has a robust proconvulsant effect and induced neuronal hyperexcitability, which is accompanied by changes in synaptic composition. We also demonstrated that PF-2545920 enhances the phosphorylation of GluA1 at Ser845. To our knowledge, this is the first study to investigate the effects of PF-2545920 on SE. A full understanding of this drug will guide its clinical use.

\section{AUTHOR CONTRIBUTIONS}

BG and XW: conceived and designed the experiments. YZ, YX, YL, PF, and QY: performed the experiments and the statistical analysis. FZ, SL: analyzed and collected the data. FX and YY: wrote the manuscript. All authors contributed to preparation of the manuscript and approved the final contributions.

\section{ACKNOWLEDGMENTS}

The authors are sincerely grateful for the participation of all patients and their families in this study. We thank the Beijing Tiantan Hospital and Xuanwu Hospital of the Capital University of Medical Sciences for the brain samples. This work was supported by the National Natural Science Foundation of China (No. 81271445, 81471319, 81301110) and National Clinical Key Specialty Construction Foundation of China.

\section{SUPPLEMENTARY MATERIAL}

The Supplementary Material for this article can be found online at: http://journal.frontiersin.org/article/10.3389/fnmol. 2017.00100/full\#supplementary-material

FIGURE S1 | Negative control for each channel. PDE10A antibody (488 channel), glial fibrillary acidic protein (GFAP) antibody (549 channel) and microtubule-associated protein 2 (MAP2) antibody (405 channel) were replaced by phosphate buffered saline (PBS). In the staining, no neurons or glia was marked separately.

Barria, A., and Malinow, R. (2002). Subunit-specific NMDA receptor trafficking to synapses. Neuron 35, 345-353. doi: 10.1016/S0896-6273(02) 00776-6

Bass, A., Kinter, L., and Williams, P. (2004). Origins, practices and future of safety pharmacology. J. Pharmacol. Toxicol. Methods 49, 145-151. doi: 10.1016/ j.vascn.2004.02.007

Bender, A. T., and Beavo, J. A. (2006). Cyclic nucleotide phosphodiesterases: molecular regulation to clinical use. Pharmacol. Rev. 58, 488-520. doi: 10.1124/ pr.58.3.5

Benke, T. A., Luthi, A., Isaac, J. T., and Collingridge, G. L. (1998). Modulation of AMPA receptor unitary conductance by synaptic activity. Nature 393, 793-797. doi: $10.1038 / 31709$ 
Bonilha, L., Elm, J. J., Edwards, J. C., Morgan, P. S., Hicks, C., Lozar, C., et al. (2010). How common is brain atrophy in patients with medial temporal lobe epilepsy? Epilepsia 51, 1774-1779. doi: 10.1111/j.1528-1167.2010.02576.x

Boulton, C. L., Mccrohan, C. R., and O’shaughnessy, C. T. (1993). Cyclic AMP analogues increase excitability and enhance epileptiform activity in rat neocortex in vitro. Eur. J. Pharmacol. 236, 131-136. doi: 10.1016/0014-2999(93) 90235-A

Carhuapoma, J. R., Qureshi, A. I., Tamargo, R. J., Mathis, J. M., and Hanley, D. F. (2001). Intra-arterial papaverine-induced seizures: case report and review of the literature. Surg. Neurol. 56, 159-163. doi: 10.1016/S0090-3019(01)00450-5

Chang, P., Chandler, K. E., Williams, R. S., and Walker, M. C. (2010). Inhibition of long-term potentiation by valproic acid through modulation of cyclic AMP. Epilepsia 51, 1533-1542. doi: 10.1111/j.1528-1167.2009.02412.x

Chen, J. W., and Wasterlain, C. G. (2006). Status epilepticus: pathophysiology and management in adults. Lancet Neurol. 5, 246-256. doi: 10.1016/S1474-4422(06) 70374-X

Chen, Q., He, S., Hu, X. L., Yu, J., Zhou, Y., Zheng, J., et al. (2007). Differential roles of NR2A- and NR2B-containing NMDA receptors in activity-dependent brain-derived neurotrophic factor gene regulation and limbic epileptogenesis. J. Neurosci. 27, 542-552. doi: 10.1523/JNEUROSCI.3607-06.2007

Conti, M., and Beavo, J. (2007). Biochemistry and physiology of cyclic nucleotide phosphodiesterases: essential components in cyclic nucleotide signaling. Annu. Rev. Biochem. 76, 481-511. doi: 10.1146/annurev.biochem.76.060305.150444

Curia, G., Longo, D., Biagini, G., Jones, R. S., and Avoli, M. (2008). The pilocarpine model of temporal lobe epilepsy. J. Neurosci. Methods 172, 143-157. doi: 10. 1016/j.jneumeth.2008.04.019

Derkach, V., Barria, A., and Soderling, T. R. (1999). $\mathrm{Ca}^{2+} /$ calmodulin-kinase II enhances channel conductance of alpha-amino-3-hydroxy-5-methyl-4isoxazolepropionate type glutamate receptors. Proc. Natl. Acad. Sci. U.S.A. 96, 3269-3274. doi: 10.1073/pnas.96.6.3269

Dong, Z., Han, H., Li, H., Bai, Y., Wang, W., Tu, M., et al. (2015). Long-term potentiation decay and memory loss are mediated by AMPAR endocytosis. J. Clin. Invest. 125, 234-247. doi: 10.1172/JCI77888

Duncan, J. S., Sander, J. W., Sisodiya, S. M., and Walker, M. C. (2006). Adult epilepsy. Lancet 367, 1087-1100.

Ehlers, M. D. (2003). Activity level controls postsynaptic composition and signaling via the ubiquitin-proteasome system. Nat. Neurosci. 6, 231-242. doi: 10.1038/ $\mathrm{nn} 1013$

Francis, S. H., Blount, M. A., and Corbin, J. D. (2011). Mammalian cyclic nucleotide phosphodiesterases: molecular mechanisms and physiological functions. Physiol. Rev. 91, 651-690. doi: 10.1152/physrev.00030.2010

French, J. A. (2007). Refractory epilepsy: clinical overview. Epilepsia 48(Suppl. 1), 3-7. doi: $10.1111 / j .1528-1167.2007 .00992 . x$

Garcia, A. M., Redondo, M., Martinez, A., and Gil, C. (2014). Phosphodiesterase 10 inhibitors: new disease modifying drugs for Parkinson's disease? Curr Med. Chem. 21, 1171-1187. doi: 10.2174/09298673216661312282 21749

Giralt, A., Saavedra, A., Carreton, O., Arumi, H., Tyebji, S., Alberch, J., et al. (2013). PDE10 inhibition increases GluA1 and CREB phosphorylation and improves spatial and recognition memories in a Huntington's disease mouse model. Hippocampus 23, 684-695. doi: 10.1002/hipo.22128

Gong, N., Li, Y., Cai, G. Q., Niu, R. F., Fang, Q., Wu, K., et al. (2009). GABA transporter-1 activity modulates hippocampal theta oscillation and theta burst stimulation-induced long-term potentiation. J. Neurosci. 29, 15836-15845. doi: 10.1523/JNEUROSCI.4643-09.2009

Grauer, S. M., Pulito, V. L., Navarra, R. L., Kelly, M. P., Kelley, C., Graf, R., et al. (2009). Phosphodiesterase 10A inhibitor activity in preclinical models of the positive, cognitive, and negative symptoms of schizophrenia. J. Pharmacol. Exp. Ther. 331, 574-590. doi: 10.1124/jpet.109.155994

Guibinga, G. H., Murray, F., and Barron, N. (2013). HPRT-deficiency dysregulates cAMP-PKA signaling and phosphodiesterase 10A expression: mechanistic insight and potential target for Lesch-Nyhan Disease? PLoS ONE 8:e63333. doi: 10.1371/journal.pone.0063333

Harada, A., Suzuki, K., and Kimura, H. (2017). TAK-063, a novel phosphodiesterase 10A inhibitor, protects from striatal neurodegeneration and ameliorates behavioral deficits in the R6/2 mouse model of Huntington's Disease. J. Pharmacol. Exp. Ther. 360, 75-83. doi: 10.1124/jpet.116. 237388
Hauser, W. A., Annegers, J. F., and Kurland, L. T. (1993). Incidence of epilepsy and unprovoked seizures in Rochester, Minnesota: 1935-1984. Epilepsia 34, 453-468. doi: 10.1111/j.1528-1157.1993.tb02586.x

Higashima, M., Ohno, K., and Koshino, Y. (2002). Cyclic AMP-mediated modulation of epileptiform afterdischarge generation in rat hippocampal slices. Brain Res. 949, 157-161. doi: 10.1016/S0006-8993(02)02976-1

Kahramaner, Z., Erdemir, A., Turkoglu, E., Cosar, H., Sutcuoglu, S., and Ozer, E. A. (2014). Papaverine intoxication in a newborn: an unusual case report. Turk. J. Pediatr. 56, 532-534.

Lau, C. G., and Zukin, R. S. (2007). NMDA receptor trafficking in synaptic plasticity and neuropsychiatric disorders. Nat. Rev. Neurosci. 8, 413-426. doi: 10.1038/ nrn2153

Lee, D. (2015). Global and local missions of cAMP signaling in neural plasticity, learning, and memory. Front. Pharmacol. 6:161. doi: 10.3389/fphar.2015.00161

Leuti, A., Laurenti, D., Giampa, C., Montagna, E., Dato, C., Anzilotti, S., et al. (2013). Phosphodiesterase 10A (PDE10A) localization in the R6/2 mouse model of Huntington's disease. Neurobiol. Dis. 52, 104-116. doi: 10.1016/j.nbd.2012. 11.016

Li, N., Lee, K., Xi, Y., Zhu, B., Gary, B. D., Ramirez-Alcantara, V., et al. (2015). Phosphodiesterase 10A: a novel target for selective inhibition of colon tumor cell growth and beta-catenin-dependent TCF transcriptional activity. Oncogene 34, 1499-1509. doi: 10.1038/onc.2014.94

Liddie, S., Anderson, K. L., Paz, A., and Itzhak, Y. (2012). The effect of phosphodiesterase inhibitors on the extinction of cocaine-induced conditioned place preference in mice. J. Psychopharmacol. 26, 1375-1382. doi: 10.1177/ 0269881112447991

Loddenkemper, T., Talos, D. M., Cleary, R. T., Joseph, A., Sanchez Fernandez, I., Alexopoulos, A., et al. (2014). Subunit composition of glutamate and gammaaminobutyric acid receptors in status epilepticus. Epilepsy Res. 108, 605-615. doi: 10.1016/j.eplepsyres.2014.01.015

Logrip, M. L., Vendruscolo, L. F., Schlosburg, J. E., Koob, G. F., and Zorrilla, E. P. (2014). Phosphodiesterase 10A regulates alcohol and saccharin selfadministration in rats. Neuropsychopharmacology 39, 1722-1731. doi: 10.1038/ npp. 2014.20

Loscher, W., and Brandt, C. (2010). Prevention or modification of epileptogenesis after brain insults: experimental approaches and translational research. Pharmacol. Rev. 62, 668-700. doi: 10.1124/pr.110.003046

Mu, Y., Ren, Z., Jia, J., Gao, B., Zheng, L., Wang, G., et al. (2014). Inhibition of phosphodiesterase $10 \mathrm{~A}$ attenuates morphine-induced conditioned place preference. Mol. Brain 7, 70. doi: 10.1186/s13041-014-0070-1

Niccolini, F., Foltynie, T., Reis Marques, T., Muhlert, N., Tziortzi, A. C., Searle, G. E., et al. (2015). Loss of phosphodiesterase 10A expression is associated with progression and severity in Parkinson's disease. Brain 138, 3003-3015. doi: 10.1093/brain/awv219

Nishi, A., Kuroiwa, M., Miller, D. B., O'callaghan, J. P., Bateup, H. S., Shuto, T., et al. (2008). Distinct roles of PDE4 and PDE10A in the regulation of cAMP/PKA signaling in the striatum. J. Neurosci. 28, 10460-10471. doi: 10. 1523/JNEUROSCI.2518-08.2008

Opazo, P., Labrecque, S., Tigaret, C. M., Frouin, A., Wiseman, P. W., De Koninck, P., et al. (2010). CaMKII triggers the diffusional trapping of surface AMPARs through phosphorylation of stargazin. Neuron 67, 239-252. doi: 10. 1016/j.neuron.2010.06.007

Palencia, A., Crépin, T., Vu, M. T., Lincecum, T. L. Jr., Martinis, S. A., and Cusack, S. (2012). Structural dynamics of the aminoacylation and proofreading functional cycle of bacterial leucyl-tRNA synthetase. Nat. Struct. Mol. Biol. 19, 677-684. doi: 10.1038/nsmb.2317

Piccart, E., Gantois, I., Laeremans, A., De Hoogt, R., Meert, T., Vanhoof, G., et al. (2011). Impaired appetitively as well as aversively motivated behaviors and learning in PDE10A-deficient mice suggest a role for striatal signaling in evaluative salience attribution. Neurobiol. Learn. Mem. 95, 260-269. doi: 10.1016/j.nlm.2010.11.018

Piccart, E., Langlois, X., Vanhoof, G., and D’hooge, R. (2013). Selective inhibition of phosphodiesterase 10A impairs appetitive and aversive conditioning and incentive salience attribution. Neuropharmacology 75, 437-444. doi: 10.1016/ j.neuropharm.2013.08.006

Porsolt, R. D., Lemaire, M., Durmuller, N., and Roux, S. (2002). New perspectives in CNS safety pharmacology. Fundam. Clin. Pharmacol. 16, 197-207. doi: 10. 1046/j.1472-8206.2002.00061.x 
Racine, R. J. (1972). Modification of seizure activity by electrical stimulation. II. Motor seizure. Electroencephalogr. Clin. Neurophysiol. 32, 281-294. doi: 10.1016/0013-4694(72)90177-0

Rajasekaran, K., Joshi, S., Kozhemyakin, M., Todorovic, M. S., Kowalski, S., Balint, C., et al. (2013). Receptor trafficking hypothesis revisited: plasticity of AMPA receptors during established status epilepticus. Epilepsia 54(Suppl. 6), 14-16. doi: 10.1111/epi.12266

Rajasekaran, K., Todorovic, M., and Kapur, J. (2012). Calcium-permeable AMPA receptors are expressed in a rodent model of status epilepticus. Ann. Neurol. 72, 91-102. doi: 10.1002/ana.23570

Rakhade, S. N., and Jensen, F. E. (2009). Epileptogenesis in the immature brain: emerging mechanisms. Nat. Rev. Neurol. 5, 380-391. doi: 10.1038/nrneurol. 2009.80

Rodefer, J. S., Saland, S. K., and Eckrich, S. J. (2012). Selective phosphodiesterase inhibitors improve performance on the $\mathrm{ED} / \mathrm{ID}$ cognitive task in rats. Neuropharmacology $\quad 62, \quad 1182-1190$. doi: 10.1016/j.neuropharm.2011. 08.008

Russwurm, C., Koesling, D., and Russwurm, M. (2015). Phosphodiesterase 10A Is tethered to a synaptic signaling complex in striatum. J. Biol. Chem. 290, 11936-11947. doi: 10.1074/jbc.M114.595769

Scannevin, R. H., and Huganir, R. L. (2000). Postsynaptic organization and regulation of excitatory synapses. Nat. Rev. Neurosci. 1, 133-141. doi: 10.1038/ 35039075

Scharfman, H. E. (2007). The neurobiology of epilepsy. Curr. Neurol. Neurosci. Rep. 7, 348-354. doi: 10.1007/s11910-007-0053-z

Seeger, T. F., Bartlett, B., Coskran, T. M., Culp, J. S., James, L. C., Krull, D. L., et al. (2003). Immunohistochemical localization of PDE10A in the rat brain. Brain Res. 985, 113-126. doi: 10.1016/S0006-8993(03)02754-9

Siuciak, J. A., Mccarthy, S. A., Chapin, D. S., Fujiwara, R. A., James, L. C., Williams, R. D., et al. (2006). Genetic deletion of the striatum-enriched phosphodiesterase PDE10A: evidence for altered striatal function. Neuropharmacology 51, 374-385. doi: 10.1016/j.neuropharm.2006.01.012

Soderling, S. H., Bayuga, S. J., and Beavo, J. A. (1999). Isolation and characterization of a dual-substrate phosphodiesterase gene family: PDE10A. Proc. Natl. Acad. Sci. U.S.A. 96, 7071-7076.
Sombati, S., and Delorenzo, R. J. (1995). Recurrent spontaneous seizure activity in hippocampal neuronal networks in culture. J. Neurophysiol. 73, 1706-1711.

Sutula, T., He, X. X., Cavazos, J., and Scott, G. (1988). Synaptic reorganization in the hippocampus induced by abnormal functional activity. Science 239, 1147-1150.

Suzuki, K., Harada, A., Suzuki, H., Miyamoto, M., and Kimura, H. (2016). TAK063, a PDE10A inhibitor with balanced activation of direct and indirect pathways, provides potent antipsychotic-like effects in multiple paradigms. Neuropsychopharmacology 41, 2252-2262. doi: 10.1038/npp.2016.20

Tang, B., Luo, D., Yang, J., Xu, X. Y., Zhu, B. L., Wang, X. F., et al. (2015). Modulation of AMPA receptor mediated current by nicotinic acetylcholine receptor in layer I neurons of rat prefrontal cortex. Sci. Rep. 5:14099. doi: $10.1038 /$ srep 14099

Thom, M. (2014). Review: hippocampal sclerosis in epilepsy: a neuropathology review. Neuropathol. Appl. Neurobiol. 40, 520-543. doi: 10.1111/nan.12150

Xu, X., Hu, Y., Xiong, Y., Li, Z., Wang, W., Du, C., et al. (2015). Association of microtubule dynamics with chronic epilepsy. Mol. Neurobiol. 53, 5013-5024. doi: 10.1007/s12035-015-9431-8

Zaccara, G., Giovannelli, F., Cincotta, M., and Iudice, A. (2013). AMPA receptor inhibitors for the treatment of epilepsy: the role of perampanel. Expert Rev. Neurother. 13, 647-655. doi: 10.1586/ern.13.46

Zhang, Y., Chen, G., Gao, B., Li, Y., Liang, S., Wang, X., et al. (2016). NR4A1 knockdown suppresses seizure activity by regulating surface expression of NR2B. Sci. Rep. 6:37713. doi: 10.1038/srep37713

Conflict of Interest Statement: The authors declare that the research was conducted in the absence of any commercial or financial relationships that could be construed as a potential conflict of interest.

Copyright (C) 2017 Zhang, Gao, Zheng, Lu, Li, Xiong, Yang, Yang, Fu, Xiao and Wang. This is an open-access article distributed under the terms of the Creative Commons Attribution License (CC BY). The use, distribution or reproduction in other forums is permitted, provided the original author(s) or licensor are credited and that the original publication in this journal is cited, in accordance with accepted academic practice. No use, distribution or reproduction is permitted which does not comply with these terms. 